\title{
Trypsin treatment unlocks barrier for zoonotic coronaviruses infection.
}

Vineet D. Menachery',2, a; Kenneth H. Dinnon III2,3, a; Boyd L. Yount Jr.2; Eileen T. McAnarney ${ }^{1,2}$; Lisa E. Gralinski; Andrew Hale ${ }^{3}$; Rachel L. Graham²; Trevor Scobey2; Simon J. Anthony ${ }^{4,5}$;, Lingshu Wang ${ }^{6}$, Barney Graham ${ }^{6}$, Scott H. Randell7, W. lan Lipkin ${ }^{4,5}$; Ralph S. Baric ${ }^{2,3}$

\begin{abstract}
${ }^{a}$ Co-first Authors
${ }^{1}$ Department of Microbiology and Immunology, University of Texas Medical Branch, Galveston, TX 77555 ${ }^{2}$ Department of Epidemiology, Gillings School of Global Public Health, University of North Carolina at Chapel Hill, NC 27514

${ }^{3}$ Department of Microbiology and Immunology, University of North Carolina School of Medicine, Chapel Hill, NC 27514

${ }^{4}$ Center for Infection and Immunity, Mailman School of Public Health, Columbia University, New York, NY, 10032

${ }^{5}$ Dept of Epidemiology, Mailman School of Public Health, Columbia University, New York, NY

${ }^{6}$ Vaccine Research Center, National Institute of Allergy and Infectious Diseases, Bethesda, MD 20892

${ }^{7}$ Department of Cell Biology and Physiology, and Marsico Lung Institute/Cystic Fibrosis Center, University of North Carolina at Chapel Hill, NC 27514
\end{abstract}

Corresponding Author: Ralph S. Baric

Address: University of North Carolina at Chapel Hill, 2107 McGavran-Greenberg Hall CB 7435, Chapel Hill, NC 27599-7435

Telephone: 919-966-7991 Fax: 919-966-0584

Email: Rbaric@email.unc.edu

Running Title: Trypsin unlocks barrier for zoonotic CoV infection.

Keywords: coronavirus, MERS-CoV, zoonotic, PDF2180, emergence 


\section{Abstract}

2 Traditionally, the emergence of coronaviruses (CoVs) has been attributed to a gain in receptor

3 binding in a new host. Our previous work with SARS-like viruses argued that bats already

4 harbor CoVs with the ability to infect humans without adaptation. These results suggested that

5 additional barriers limit the emergence of zoonotic CoV. In this work, we describe overcoming

6 host restriction of two MERS-like bat CoVs using exogenous protease treatment. We found that

7 the spike protein of PDF2180-CoV, a MERS-like virus found in a Ugandan bat, could mediate

8 infection of Vero and human cells in the presence of exogenous trypsin. We subsequently show

9 that the bat virus spike can mediate infection of human gut cells, but is unable to infect human

10 lung cells. Using receptor-blocking antibodies, we show that infection with the PDF2180 spike

11 does not require MERS-CoV receptor DPP4 and antibodies developed against the MERS spike

12 receptor-binding domain and S2 portion are ineffective in neutralizing the PDF2180 chimera.

13 Finally, we found that addition of exogenous trypsin also rescues replication of HKU5-CoV, a

14 second MERS-like group 2c CoV. Together, these results indicate that proteolytic cleavage of

15 the spike, not receptor binding, is the primary infection barrier for these two group 2c CoVs.

16 Coupled with receptor binding, proteolytic activation offers a new parameter to evaluate

17 emergence potential of CoVs and offer a means to recover previously unrecoverable zoonotic

18 CoV strains.

19 Importance

20 Overall, our studies demonstrate that proteolytic cleavage is the primary barrier to infection for a

21 subset of zoonotic coronaviruses. Moving forward, the results argue that both receptor binding

22 and proteolytic cleavage of the spike are critical factors that must be considered for evaluating

23 the emergence potential and risk posed by zoonotic coronaviruses. In addition, the findings also

24 offer a novel means to recover previously uncultivable zoonotic coronavirus strains and argue

25 that other tissues, including the digestive tract, could be a site for future coronavirus emergence

26 events in humans. 


\section{Introduction}

Since the beginning of the $21^{\text {st }}$ century, public health infrastructures have been required

29 to periodically respond to new and reemerging zoonotic viral diseases, including influenza,

30 Ebola, and Zika virus outbreaks (1). Severe acute respiratory syndrome coronavirus (SARS-

$31 \mathrm{CoV})$, the first major outbreak of the century, highlighted the global impact of a newly emerging

32 virus in the context of expanding development, increased globalization, and poor public health

33 infrastructures (2-4). A decade later, the emergence and continued outbreaks of the Middle East

34 respiratory syndrome coronavirus (MERS-CoV) further illustrate the ongoing threat posed by

35 circulating zoonotic viruses (5). Together, the outbreaks of the early part of this century argue

36 that continued preparations and vigilance are needed to maintain global public health.

Despite their spontaneous emergence, several research approaches to rapidly respond

and even predict outbreak strains already exist. During the MERS-CoV outbreak, our group and others were able to leverage reagents generated against related group 2C coronaviruses,

40 HKU4- and HKU5-CoV $(6,7)$. These reagents, created independent of viable virus replication,

41 provided valuable insights and models for testing serologic responses during the early stages of

42 the MERS-CoV outbreak. Similarly, reverse genetics systems permitted the exploration of

43 zoonotic coronaviruses (8); using the known SARS spike/ACE2 receptor interaction, chimeric

44 viruses containing the backbones of bat CoVs were generated to evaluate the efficacy of both

45 vaccines and therapeutics (9-12). The inverse approach placed the zoonotic spike proteins in

46 the context of the epidemic SARS-CoV backbone $(13,14)$. These studies provided insight into

47 potential threats circulating in bats as well as the efficacy of current therapeutic treatments (15).

48 While far from comprehensive, the results indicated that these approaches, reagents, and

49 predictions may prove useful in preparations for future CoV outbreaks.

50 In this study, we extend examination of zoonotic viruses to a novel MERS-like CoV strain

51 isolated from a Ugandan bat, PDF-2180 CoV (MERS-Uganda). Our initial attempt to cultivate a

52 chimeric MERS-CoV containing the Ugandan MERS-like spike produced viral sub-genomic 
53 transcripts, but failed to result in infectious virus after electroporation (16). However, in the

54 current study, we demonstrate that exogenous trypsin treatment produced high-titer virus

55 capable of plaque formation and continued replication. The chimeric Ugandan MERS-like spike

56 virus could replicate efficiently in both Vero and Huh7 cells in the context of trypsin-containing

57 media, but failed to produce infection of either continuous or primary human respiratory cell

58 cultures. Importantly, the MERS-Uganda chimeric virus successfully infected cells of the human

59 digestive tract, potentially identifying another route for cross-species transmission and

60 emergence. Notably, blockade of human DPP4, the receptor for MERS-CoV, had no significant

61 impact on replication of the chimeric MERS-Uganda virus, suggesting the use of an alternative

62 receptor. Similarly, addition of trypsin also rescued replication of full-length HKU5-CoV, a

63 related group 2C bat CoV, and showed no replication defect during DPP4 blockade. Together,

64 the results indicate that proteolytic activation of the spike protein is a potent constraint to

65 infection for zoonotic CoVs and expands the correlates for CoV emergence beyond receptor

66 binding alone. 


\section{Results}

Utilizing the MERS-CoV infectious clone (17), we previously attempted to evaluate the potential

70 of the PDF-2180 CoV to emerge from zoonotic populations. Replacing the wild-type MERS-CoV

71 spike with the PDF-2180 spike produced a virus capable of generating viral transcripts in vitro,

72 but not sustained replication (16). These results suggested that the significant amino acid

73 differences observed within the receptor-binding domain precluded infection of Vero cells.

74 However, amino acid changes were not confined only to the receptor-binding domain (RBD);

75 highlighting changes between the Uganda spike on the MERS-CoV trimer revealed significant

76 differences throughout the $S 1$ region of spike (Fig. 1A \& B). While the S2 remained highly

77 conserved (Fig. 1C), changes in the $\mathrm{C}$ - and N-terminal domains of $\mathrm{S} 1$, in addition to the RBD,

78 may also influence entry and infection compatibility. Notably, recent reports had also indicated

79 differential protease cleavage of wild-type MERS-CoV based on cell types, suggesting that

80 spike processing influences docking and entry of pseudotyped virus (18). To explore if spike

81 cleavage impaired infectivity, we evaluated MERS-Uganda virus replication in the presence of

82 trypsin-containing media. The addition of trypsin to the chimeric virus resulted in cytopathic

83 effect, fusion of the Vero monolayer, formation of plaques under a trypsin-containing overlay,

84 and collection of high-titer infectious virus stock (Fig. 1D). The requirement for trypsin

85 complicated these studies due to cell toxicity; to overcome this issue, we utilized both trypsin-

86 adapted Vero cells and a MERS-Uganda chimera encoding RFP in place of ORF5, similar to a

87 previously generated MERS-CoV reporter virus (17). Following MERS-Uganda infection,

88 cultures with trypsin containing media showed evidence for replication of viral genomic RNA

89 (Fig. 1E). Similarly, the nucleocapsid protein was only observed in the presence of exogenous

90 trypsin following infection with the MERS-Uganda chimera (Fig. 1F). Notably, wild-type MERS-

91 CoV was also augmented in the presence of trypsin with increased genomic RNA and

92 nucleocapsid protein relative to no trypsin control (Fig. 1E \&F). Examination of RFP signal

93 confirmed these RNA and protein results (Fig. 1G), as RFP was only observed in MERS- 
94 Uganda chimeric infection in the presence of trypsin. Similarly, RFP expression was more

95 robust in trypsin-treated cells following MERS-CoV infection. Together, these data indicate that

96 the PDF-2180 spike can mediate infection of Vero cells in a trypsin-dependent manner.

\section{$97 \quad$ MERS-Uganda spike replicates in human cells}

98 Having demonstrated infection and replication, we next sought to determine the capacity of

99 MERS-Uganda chimeric virus to grow in human cells. Previously, MERS-CoV had been shown

100 to replicate efficiently in Huh7 cells (19). Using the Huh7 liver cell line, infection with MERS-

101 Uganda RFP chimeric virus resulted in RFP-positive cells and cell fusion (Fig. 2A). In contrast,

102 while a few RFP-positive cells were observed in the non-trypsin-treated group, neither

103 expanding RFP expression nor cytopathic effect were seen in the absence of trypsin. Our

104 observation may have been the result of residual trypsin activity from the undiluted virus stock,

105 resulting in low-level infection. Exploring further, $\mathrm{N}$ protein analysis by Western blot indicated

106 that the PDF-2180 spike chimera could produce significant viral proteins in the presence of

107 trypsin (Fig. 2B); only low levels of protein were observed in the control-treated infection. While

108 replication of the MERS-Uganda chimera was not equivalent to that of wild-type MERS-CoV, the

109 results clearly demonstrate the capacity of the PDF-2180 spike to mediate infection of human

110 cells in the presence of trypsin.

111 We next examined the capacity of MERS-Uganda spike to infect human respiratory

112 cells, the primary targets of SARS-CoV, MERS-CoV, and other common-cold human CoVs.

113 Using Calu3 cells, a human lung epithelial cell line, we observed robust replication of wild-type

114 MERS-CoV based on RFP expression, consistent with previous studies (17). However, no

115 evidence of infection was noted in MERS-Uganda-infected Calu3 cells in the presence or

116 absence of trypsin. We subsequently explored primary human airway epithelial (HAE) cultures.

117 Grown on an air-liquid interface, HAE cultures have a propensity to facilitate improved

118 infections of several human CoVs and may be more permissive for infection with the PDF-2180

119 spike chimera (20). However, infection with PDF-2180 spike-containing virus showed no 
120 evidence of RFP expression, even after several trypsin washes of the apical surface (Fig. 2C).

121 Similarly, RNA expression analysis found no evidence for accumulation of viral genomic RNA,

122 indicating no evidence for replication in HAE cultures (Fig. 2D). In contrast, wild-type MERS-

123 CoV efficiently infects these HAE cultures, as demonstrated by both RFP expression and viral

124 genomic RNA accumulation. Together, the Calu3 and HAE results suggest that the PDF-2180

125 spike is unable to infect respiratory cells in humans, even in the presence of exogenous trypsin.

126 We next evaluated the capacity of the PDF-2180 chimera to infect cells of the digestive

127 tract. While uncommon in humans, several animal CoVs have been shown to cause severe

128 disease via the enteric pathway $(21,22)$. In addition, most bat CoV sequences, including PDF-

129 2180-CoV, were isolated from bat guano samples, suggesting an enteric etiology. Importantly,

130 the presence of trypsin and other soluble host proteases in the digestive tract may facilitate

131 infection with PDF-2180 spike in humans. To test this question, we infected Caco-2 cells, a

132 human epithelial colorectal adenocarcinoma cell line, with wild-type MERS-CoV and MERS-

133 Uganda spike chimera in the presence or absence of trypsin (Fig. 2E). For MERS-CoV,

134 infection of Caco-2 cells resulted in robust infection and spread with or without trypsin in the

135 media. For the MERS-Uganda chimera, the addition of trypsin facilitated infection with abundant

136 RFP-positive Caco-2 cells; however, infection was not as robust as in the wild-type MERS-CoV

137 infection. Examination of $\mathrm{N}$ protein by Western blot indicated that the MERS-Uganda spike

138 could produce infection in Caco-2 cells, but confirmed replication at levels lower than with wild-

139 type MERS-CoV (Fig. 2F). Together, the results indicate that human cells, including gut cells,

140 can support infection with MERS-Uganda chimera in the presence of trypsin.

\section{MERS-Uganda spike does not use DPP4 for entry}

142 The absence of infection of human respiratory cells coupled with significant changes in the RBD

143 suggested that MERS-Uganda does not utilize the MERS-CoV receptor, human DPP4, for entry

144 (16). To explore this question, we utilized antibodies to block DPP4 in Vero cells to determine

145 the effect on MERS-Uganda chimeric virus replication. As expected, anti-DPP4 antibody 
146 successfully ablated replication of wild-type MERS-CoV in both the presence and the absence

147 of trypsin treatment, as measured by both RFP and N protein expression (Fig. 3A \& B). In

148 contrast, the human DPP4-blocking antibody had no impact on infection with the MERS-Uganda

149 chimera virus in the presence of trypsin, confirming that the MERS-CoV receptor is not required

150 to mediate infection with the PDF-2180 spike. Together, these results indicate that while the

151 MERS-Uganda spike infects human cells, it does not require human DPP4 to mediate infection.

152 MERS-CoV therapeutics are ineffective against MERS-Uganda spike.

153 Having established replication capacity in human cells, we next sought to determine if

154 therapeutics developed against the MERS-CoV spike could disrupt infection with the MERS-

155 Uganda spike chimera. Several monoclonal antibodies have been identified as possible

156 therapeutic options for treatment of MERS-CoV, including LCA60 and G4. We first evaluated

157 LCA60, a potent antibody that binds adjacent to the spike RBD of MERS-CoV (23). However,

158 the major changes in the RBD region of MERS-Uganda spike predicted a lack of efficacy (Fig.

159 4A). LCA60 potently neutralized wild-type MERS-CoV grown in both the presence and the

160 absence of tyrpsin (Fig. 4B). However, consistent with expectations, the LCA60 antibody had

161 no impact on infection with the MERS-Uganda chimera, failing to neutralize the bat spike-

162 expressing virus (Fig. 4B). We subsequently examined a second monoclonal antibody, G4,

163 which had previously mapped to a conserved portion of the S2 region of the MERS-spike (Fig.

164 4A) (24). With the epitope relatively conserved in MERS-Uganda spike, we tested the efficacy

165 against the zoonotic spike chimera. However, the results demonstrate no neutralization of

166 MERS-Uganda spike virus by the S2-targeted antibody (Fig. 4C). Notably, G4 also failed to

167 neutralize wild-type MERS-CoV grown in the the presence of exogenous trypsin (Fig. 4C).

168 Together, the results indicate that both group 2C CoV spikes could escape neutralization by the

169 S2-targeted antibody in the presence of exogenous trypsin. Overall, these experiments suggest

170 that antibodies targeted against MERS-CoV, even to regions in the highly conserved S2

171 domain, may not have utility against viruses expressing the PDF-2180 spike. 


\section{Trypsin treatment rescues the replication of zoonotic HKU5-CoV}

173 Based on the MERS-Uganda chimera virus, we wondered if a similar barrier prevented

174 replication of other zoonotic CoVs. Previously, our group had generated a full-length infectious

175 clone for HKU5-CoV, another group 2C coronavirus sequence isolated from bats. Similar to the

176 MERS-Uganda chimera, the infectious clone of HKU5-CoV produced sub-genomic transcripts,

177 but failed to achieve productive infection (6). Revisiting the full-length recombinant virus, we

178 sought to determine if trypsin treatment could also rescue HKU5-CoV. Following HKU5-CoV

179 infection, addition of trypsin to the media resulted in cytopathic effect and cell fusion. In contrast,

180 cultures lacking trypsin showed no signs of viral infection. Exploring viral genomic RNA, trypsin

181 in the culture media permitted robust infection with HKU5-CoV that increased over time and was

182 absent in cells not treated with trypsin (Fig. 5A). Similarly, trypsin in the media also permitted

183 the accumulation and proteolytic cleavage of the HKU5 spike protein in a dose and time

184 dependent manner (Fig. 5B). Importantly, the addition of anti-DPP4 antibody had no impact on

185 HKU5-CoV infection, suggesting the use of a different receptor than used by wild-type MERS-

186 CoV, similar to the findings with MERS-Uganda spike (Fig. 5C). Together, these results

187 demonstrate that protease cleavage is a primary barrier to infection of Vero cells with HKU5-

188 CoV. 


\section{Discussion}

190 In this manuscript, we expanded our examination of circulating zoonotic viruses and identified

191 protease cleavage as an important barrier to emergence of some group 2C zoonotic CoVs. The

192 chimeric virus containing the spike protein from PDF-2180 was capable of replication in Vero

193 cells and human cells (Huh7, Caco-2) if treated with exogenous trypsin. However, neither

194 continuous nor primary human airway cultures were susceptible to infection, contrasting wild-

195 type MERS-CoV. The MERS-Uganda chimera also maintained replication despite treatment

196 with antibodies blocking human DPP4, suggesting use of either an alternative receptor or a

197 different entry mechanism for infection. Importantly, current therapeutics targeting the MERS

198 spike protein showed no efficacy against the MERS-Uganda chimera, highlighting a potential

199 public health vulnerability to this and related group 2C CoVs. Finally, the trypsin-mediated

200 rescue of a second zoonotic group $2 \mathrm{C} \mathrm{CoV}$, HKU5-CoV, validates findings that suggested that

201 protease cleavage may represent a critical barrier to zoonotic CoV infection in new hosts (25,

202 26). Together, the results highlight the importance of spike processing in CoV infection, expand

203 the correlates associated with emergence beyond receptor binding alone, and provide a

204 platform strategy to recover previously non-cultivatable zoonotic CoVs.

205 With the ongoing threat posed by circulating zoonotic viruses, understanding the barriers

206 for viral emergence represents a critical area of research. For CoVs, receptor binding has been

207 believed to be the primary constraint to infection in new host populations. Following the SARS-

208 CoV outbreak, emergence in humans was attributed to mutations within the receptor-binding

209 domain that distinguished the epidemic strain from progenitor viruses harbored in bats and

210 civets (27). Yet, work by our group and others has indicated that zoonotic SARS-like viruses

211 circulating in Southeast Asian bats are capable of infecting human cells by binding to the known

212 human ACE2 receptor without adaptation $(13,14,28)$. Similarly, pseudotyped virus studies

213 have identified zoonotic strains HKU4-CoV and NL140422-CoV as capable of binding to human

214 DPP4 without mutations to the spike $(26,29)$. In this study, we demonstrate that both PDF-2180 
215 and HKU5-CoV spikes are capable of binding to and infecting human cells if primed by trypsin

216 cleavage. Together, the results argue that several circulating zoonotic CoV strains have the

217 capacity to bind to human cells without adaption and that receptor binding may not be the only

218 barrier to CoV emergence.

219 Data from this study implicates the processing of the spike protein as a critical factor for

220 CoV infection. In the absence of trypsin, the MERS-Uganda and HKU5-CoV spikes were unable

221 to mediate infection and initially suggested a lack of receptor compatibility $(6,16)$. However,

222 exogenous trypsin treatment produced robust infection, indicating that despite binding to human

223 cells, CoVs cannot overcome incomplete spike processing. As such, evaluating zoonotic virus

224 populations for emergence threats must also consider the capacity for CoV spike activation in

225 addition to receptor binding. In this new paradigm, the combination of receptor binding and

226 proteolytic activation by endogenous proteases permits zoonotic CoV infection, as with MERS-

227 CoV and SARS-CoV (Fig. 6). The absence of receptor binding (Fig. 6A) or compatible host

228 protease activity (Fig. 6B) restricts infection with certain zoonotic strains like PDF-2180 or

229 HKU5-CoV. These barriers can be overcome with the addition of exogenous proteases,

230 disrupting the need for host proteases and permitting receptor-dependent or receptor-

231 independent entry (Fig. 6C). Overall, the new paradigm argues that both receptor binding and

232 protease activation barriers must be overcome for successful zoonotic CoV infection of a new

233 host.

234 The requirement for exogenous trypsin treatment is not unique to MERS-Uganda or

235 HKU5-CoV. Influenza strains are well known to require trypsin treatment to facilitate their

236 release in cell culture (30). In addition, highly pathogenic avian influenza strains have been

237 linked to mutations that improve cleavage by ubiquitous host protese, augmenting their tissue

238 tropism and virulence (31). Similarly, a wealth of enteric viruses, including polio, cowpox, and

239 rotaviruses, depend on trypsin to prime, modulate, and/or expand infection $(32,33)$. Even within

240 the CoV family, enteric viruses, including PEDV, porcine delta CoV, and swine acute diarrhea 
241 syndrome (SADS) CoV require trypsin for replication in vitro (34-36). Together, these prior

242 studies illustrate the importance of protease activation in virus infections. However, the protease

243 barrier to PDF-2180 and HKU5-CoV spike-mediated infection may also reflect on the

244 emergence of SARS-CoV and MERS-CoV. While initial studies argued that receptor binding

245 was the primary barrier, the existence of zoonotic strains capable of efficiently using the same

246 human entry receptors contradicts that suggestion $(13,14)$. It is possible that emergence of

247 epidemic CoV strains also requires modifying protease cleavage in either humans or an

248 intermediate host, such as camels or civets, in addition to increased receptor-binding affinity.

249 Consistent with this idea, reports have detailed differential infection with MERS-CoV based on

250 host protease expression (18). Similarly, mouse adaptation of MERS-CoV resulted in spike

251 modifications that alter protease activation and entry in vivo (37). While group 2B bat CoV

252 strains (WIV1-CoV, WIV16-CoV and SHC014-CoV) do not require trypsin for infection (9, 13,

$25314,38)$, differences in protease activation may contribute to infection changes relative to the

254 epidemic SARS-CoV. In this context, our findings expand the importance of protease cleavage

255 as a criterion to consider for zoonotic virus emergence in a new host population.

256 In evaluating the threat to humans posed by PDF-2180 and HKU5-CoV, the results

257 demonstrate a pathway to emergence. Neither CoV spike uses human DPP4 for entry, and the

258 PDF-2180 chimera failed to replicate in human respiratory models, even in the presence of

259 trypsin. However, replication in Huh7 and Caco-2 cells indicates human infection compatibility

260 and may portend differential tropism, possibly in the alimentary or biliary tracts, as has been

261 described for several mammalian CoVs (34-36). MERS-Uganda or HKU5-CoV could utilize this

262 same trypsin-rich environment in the gut to emerge as an enteric pathogen in humans, although

263 its pathology and virulence would be hard to predict. Evidence from both SARS-CoV and

264 MERS-CoV outbreaks suggests the involvement of enteric pathways during infection $(39,40)$.

265 Replication in the gut might select for mutations that expand spike processing/tropism and allow

266 replication in other tissues, including the lung, and lead to virulent disease in the new host 
267 population, as seen with Porcine Respiratory Coronavirus (41). In examining the threat posed 268 by PDF-2180 and HKU5-CoV, we must consider the emergence of these CoVs in tissues other 269 than the lung and harboring distinct pathologies compared to epidemic SARS and MERS-CoV. The receptor dynamics of MERS-Uganda and HKU5-CoV also remain unclear in the 271 context of this study. In the presence of trypsin, neither spike protein requires the MERS-CoV 272 receptor, DPP4 for entry, which is consistent with the differences between the receptor-binding 273 domains of the bat and epidemic strains. Therefore, it was not surprising that antibodies that 274 target the RBD of the MERS-CoV spike were ineffective in blocking infection of the PDF-2180 275 chimera. However, the S2-targeted antibody, G4, also had no efficacy against MERS-Uganda, 276 despite a relatively conserved binding epitope. This result is possibly explained by differing 277 amino acid sequences between MERS-CoV and PDF-2180 at the G4 epitope, specifically 278 residue 1175, which is associated with G4 escape mutants in MERS-CoV (24). Alternatively, the 279 G4 antibody also failed to neutralize wild-type MERS-CoV grown in the presence of trypsin, 280 indicating that entry is still possible, despite treatment with antibody binding the S2 domain. 281 Conversely, the presence of trypsin may prime a receptor-independent entry for the MERS282 Uganda chimera, similar to the JHVM strain of MHV (42). Yet, this result would contrast PEDV, 283 which requires receptor binding prior to trypsin activation to facilitate infection (35). Importantly, 284 the lack of infection in respiratory cells suggests that some receptor or attachment factor is 285 necessary to mediate entry with the PDF-2180 spike. Recent work with MERS-CoV binding 286 sialic acid supports this idea (43) and indicates that the PDF-2180 spike may not have a similar 287 binding motif. Ovrall, further experimental studies are required to fully understand the receptor 288 dynamics of the PDF-2180 spike.

289 While providing a new strategy to recover zoonotic CoVs, this manuscript highlights 290 proteolytic cleavage of the spike as a major barrier to group 2C zoonotic CoV infection. For both 291 MERS-Uganda and HKU5-CoV, the addition of exogenous trypsin rescues infection, indicating 292 that spike cleavage, not receptor binding, limits these strains in new hosts and tissues. The 
293 adaptation of the protease cleavage sites or infection of tissues with robust host protease

294 expression could permit these two zoonotic CoV strains to emerge and may pose a threat to

295 public health due to the absence of effective spike-based therapeutics. In considering cross-

296 species transmission, our results using reconstructed bat group 2C CoVs confirm spike

297 processing as a correlate associated with emergence. Adding spike processing to receptor

298 binding as primary barriers offers a new framework to evaluate the threat of emergence for

299 zoonotic CoV strains.

300 


\section{Methods}

302 Cells, viruses, in vitro infection, and plaque assays. Vero cells were grown in DMEM (Gibco,

303 CA) supplemented with 5\% FetalClone II (Hyclone, UT) and antibiotic/antimycotic (anti/anti)

304 (Gibco, CA). Huh7 cells were grown in DMEM supplemented with $10 \%$ FetalClone II and

305 anti/anti. Caco-2 cells were grown in MEM (Gibco, CA) supplemented with 20\% Fetal Bovine

306 Serum (Hyclone, UT) and anti/anti. Human airway epithelial cell (HAE) cultures were obtained

307 from the UNC CF Center Tissue Procurement and Cell Culture Core from human lungs

308 procured under Univeristy of North Carolina at Chapel Hill Institutional Review Board-approved

309 protocols. Wild-type MERS-CoV, chimeric MERS-Uganda and HKU5-CoV were cultured on

310 Vero cells in OptiMEM (Gibco, CA) supplemented with anti/anti. For indicated experiments,

311 trypsin (Gibco, CA) was added at $0.5 \mu \mathrm{g} / \mathrm{ml}$ unless otherwise indicated.

312 Generation of wild-type MERS-CoV, MERS-Uganda, and HKU5-CoV viruses utilized

313 reverse genetics and have been previously described $(6,17,44)$. For MERS-Uganda chimera

314 expressing RFP, we utilized the MERS-CoV backbone, replacing ORF5 with RFP as previously

315 described (17). Synthetic constructions of chimeric mutant and full-length MERS-Uganda and

316 HKU5-CoV were approved by the University of North Carolina Institutional Biosafety Committee.

317 Replication in Vero, Calu-3 2B4, Caco-2, Huh7, and HAE cells was performed as previously

318 described $(12,45-47)$. Briefly, cells were washed with PBS and inoculated with virus or mock

319 diluted in OptiMEM for 60 minutes at $37^{\circ} \mathrm{C}$. Following inoculation, cells were washed 3 times,

320 and fresh media with or without trypsin was added to signify time 0 . Three or more biological

321 replicates were harvested at each described time point. For HAE cultures, apical surfaces were

322 washed with PBS containing $5 \mathrm{ug} / \mathrm{ml}$ trypsin at $0,8,18,24$, and 48 hours post infection. No

323 blinding was used in any sample collections, nor were samples randomized. Microscopy photos

324 were captured via a Keyence BZ-X700 microscope.

325 For antibody neutralization assays, MERS-CoV and MERS-Uganda stocks were grown

326 in OptiMEM both with and without trypsin. All stocks were quantified via plaque assay by 
327 overlaying cells with $0.8 \%$ agarose in OptiMEM supplemented with $0.5 \mu \mathrm{g} / \mathrm{ml}$ trypsin and 328 anti/anti. MERS-Uganda stocks grown without trypsin had low titers but were sufficient for 329 neutralization assays.

$330 \quad$ For anti-DPP4 blocking experiments, Vero cells were preincubated with serum-free

331 OptiMEM containing 5ug/ml anti-human DPP4 antibody ( $\mathrm{R} \& \mathrm{D}$ systems, MN) for one hour.

332 Media was removed and cells were infected for 1 hour with virus or mock inoculum at a

333 multiplicity of infection of 0.1 . The inoculum was removed, cells were washed three times with

334 PBS, and media was replaced.

335 RNA isolation and quantification. RNA was isolated via TRIzol reagent (Invitrogen, CA) and

336 Direct-zol RNA MiniPrep kit (Zymo Research, CA) according to the manufacturer's protocol.

337 MERS-CoV and MERS-Uganda gRNA was quantified via TaqMan Fast Virus 1-Step Master Mix

338 (Applied Biosystems, CA) using previously reported primers and probes targeting ORF1ab (47)

339 and normalized to host 18S rRNA (Applied Biosystems, CA). HKU5-CoV RNA was first reverse

340 transcribed using SuperScript III (Invitrogen) and was, CA) then assayed using SsoFast

341 EvaGreen Supermix (Bio-Rad, CA) and scaled to host GAPDH transcript levels. HKU5 gRNA

342 was amplified with the following primers: Forward - 5'-CTCTCTCTCGTTCTCTTGCAGAAC-3',

343 Reverse - 5'-GTTGAGCTCTGCTCTATACTTGCC-3'. GAPDH RNA was amplified with the

344 following primers: Forward - 5'-AGCCACATCGCTGAGACA- -3', Reverse - 5'-

345 GCCCAATACGACCAAATCC-3'. Fold change was calculated using the $\Delta \Delta \mathrm{Ct}$ method and was

346 scaled to RNA present at 0 hours post-infection.

347 Generation of VRP, polyclonal mouse antisera, and western blot analysis. Virus replicon

348 particles (VRPs) expressing the MERS-CoV nucleocapsid or HKU5-5 CoV spike were

349 constructed using a non-select BLS2 Venezuelan Equine Encephalitis (VEE) virus strain 3546

350 replicon system as previously described (48). Briefly, RNA containing the nonstructural genes of

351 VEE and either MERS-CoV nucleocapsid or HKU5-5 CoV spike was packaged using helper 
352 RNAs encoding VEE structural proteins as described previously (49). Six-week-old female

353 BALB/c mice were primed and boosted with VRPs to generate mouse anti-sera towards either

354 MERS-CoV nucleocapsid or HKU5-5 CoV spike. Following vaccination, mouse polyclonal sera

355 were collected as described previously (50). For Western blotting, lysates from infected cells

356 were prepared as described before in detail (51), and these blots were probed using the

357 indicated mouse polyclonal sera. MERS-CoV N sera was able to detect to HKU5-CoV N protein

358 via Western blot as previously described (7).

359 Virus neutralization assays. Plaque reduction neutralization titer assays were preformed with

360 previously characterized antibodies against MERS-CoV as previously described (23, 24).

361 Briefly, antibodies were serially diluted 6- to 8-fold and incubated with 80 PFU of the indicated

362 viruses for $1 \mathrm{~h}$ at $37^{\circ} \mathrm{C}$. The virus and antibodies were then added to a 6 -well plate of confluent

363 Vero cells in triplicate. After a 1 hour incubation at $37^{\circ} \mathrm{C}$, cells were overlaid with $3 \mathrm{ml}$ of $0.8 \%$

364 agarose in OptiMEM supplemented with $0.5 \mu \mathrm{g} / \mathrm{ml}$ trypsin and anti/anti. Plates were incubated

365 for 2 or 3 days at $37^{\circ} \mathrm{C}$ for MERS-CoV or MERS-Uganda, respectively, and were then stained

366 with neutral red for $3 \mathrm{~h}$, and plaques were counted. The percentage of plaque reduction was

367 calculated as [1 - (no. of plaques with antibody/no. of plaques without antibody)] 100 .

368 Biosafety and biosecurity. Reported studies were initiated after the University of North

369 Carolina Institutional Biosafety Committee approved the experimental protocols. All work for

370 these studies was performed with approved standard operating procedures (SOPs) and safety

371 conditions for MERS-CoV and other related CoVs. Our institutional CoV BSL3 facilities have

372 been designed to conform to the safety requirements recommended in Biosafety in

373 Microbiological and Biomedical Laboratories (BMBL), the U.S. Department of Health and

374 Human Services, the Public Health Service, the Centers for Disease Control (CDC) and the

375 National Institutes of Health (NIH). Laboratory safety plans have been submitted, and the facility

376 has been approved for use by the UNC Department of Environmental Health and Safety (EHS)

377 and the CDC. 


\section{Acknowledgments}

379 The research described in this manuscript was supported by grants from the United States

380 Agency for International Development (USAID) Emerging Pandemic Threats PREDICT project

381 (cooperative agreement number GHN-A-OO-09-00010-00) and from the National Institute of

382 Allergy \& Infectious Disease and the National Institute of Aging of the NIH under awards

383 U19Al109761 and Al110700 to RSB; R00AG049092 to VDM. HAE cultures were supported by

384 the National Institute of Diabetes and Digestive and Kidney Disease under award NIH

385 DK065988 to SHR. Trypsin resistant Vero cells were kindly provided by Linda Saif. Monoclonal

386 antibody LCA60 was provided by Davide Corti and Humabs Biomed SA. The content described

387 herein is solely the responsibility of the authors and does not necessarily represent the official

388 views of the $\mathrm{NIH}$.

389

390 
391

392

393

394

395

396

397

398

399

400

401

402

403

404

405

406

407

408

409

410

411

412

413

414

415

416

417

418

419

420

421

422

423

424

425

426

427

428

429

430

431

432

433

434

435

436

437

438

439

440

\section{References}

1. Reperant LA, Osterhaus A. 2017. AIDS, Avian flu, SARS, MERS, Ebola, Zika... what next? Vaccine 35:4470-4474.

2. Perlman S, Netland J. 2009. Coronaviruses post-SARS: update on replication and pathogenesis. Nat Rev Microbiol 7:439-450.

3. Morse SS, Mazet JA, Woolhouse M, Parrish CR, Carroll D, Karesh WB, ZambranaTorrelio C, Lipkin WI, Daszak P. 2012. Prediction and prevention of the next pandemic zoonosis. Lancet 380:1956-1965.

4. Cunningham AA, Daszak P, Wood JLN. 2017. One Health, emerging infectious diseases and wildlife: two decades of progress? Philos Trans R Soc Lond B Biol Sci 372.

5. Chafekar A, Fielding BC. 2018. MERS-CoV: Understanding the Latest Human Coronavirus Threat. Viruses 10.

6. Agnihothram S, Yount BL, Jr., Donaldson EF, Huynh J, Menachery VD, Gralinski LE, Graham RL, Becker MM, Tomar S, Scobey TD, Osswald HL, Whitmore A, Gopal R, Ghosh AK, Mesecar A, Zambon M, Heise M, Denison MR, Baric RS. 2014. A mouse model for Betacoronavirus subgroup $2 \mathrm{c}$ using a bat coronavirus strain HKU5 variant. MBio 5:e00047-00014.

7. Agnihothram S, Gopal R, Yount BL, Jr., Donaldson EF, Menachery VD, Graham RL, Scobey TD, Gralinski LE, Denison MR, Zambon M, Baric RS. 2014. Evaluation of serologic and antigenic relationships between middle eastern respiratory syndrome coronavirus and other coronaviruses to develop vaccine platforms for the rapid response to emerging coronaviruses. J Infect Dis 209:995-1006.

8. Johnson BA, Graham RL, Menachery VD. 2018. Viral metagenomics, protein structure, and reverse genetics: Key strategies for investigating coronaviruses. Virology 517:30-37.

9. Becker MM, Graham RL, Donaldson EF, Rockx B, Sims AC, Sheahan T, Pickles RJ, Corti D, Johnston RE, Baric RS, Denison MR. 2008. Synthetic recombinant bat SARS-like coronavirus is infectious in cultured cells and in mice. Proc Natl Acad Sci U S A 105:19944-19949.

10. Rockx B, Baas T, Zornetzer GA, Haagmans B, Sheahan T, Frieman M, Dyer MD, Teal TH, Proll S, van den Brand J, Baric R, Katze MG. 2009. Early upregulation of acute respiratory distress syndrome-associated cytokines promotes lethal disease in an aged-mouse model of severe acute respiratory syndrome coronavirus infection. J Virol 83:7062-7074.

11. Sheahan T, Rockx B, Donaldson E, Sims A, Pickles R, Corti D, Baric R. 2008. Mechanisms of zoonotic severe acute respiratory syndrome coronavirus host range expansion in human airway epithelium. J Virol 82:2274-2285.

12. Sheahan T, Rockx B, Donaldson E, Corti D, Baric R. 2008. Pathways of crossspecies transmission of synthetically reconstructed zoonotic severe acute respiratory syndrome coronavirus. J Virol 82:8721-8732.

13. Menachery VD, Yount BL, Jr., Sims AC, Debbink K, Agnihothram SS, Gralinski LE, Graham RL, Scobey T, Plante JA, Royal SR, Swanstrom J, Sheahan TP, Pickles RJ, Corti D, Randell SH, Lanzavecchia A, Marasco WA, Baric RS. 2016. SARS-like WIV1-CoV poised for human emergence. Proc Natl Acad Sci U S A 113:3048-3053.

14. Menachery VD, Yount BL, Jr., Debbink K, Agnihothram S, Gralinski LE, Plante JA, Graham RL, Scobey T, Ge XY, Donaldson EF, Randell SH, Lanzavecchia A, Marasco WA, Shi ZL, Baric RS. 2015. A SARS-like cluster of circulating bat coronaviruses shows potential for human emergence. Nat Med 21:1508-1513. 
441

442

443

444

445

446

447

448

449

450

451

452

453

454

455

456

457

458

459

460

461

462

463

464

465

466

467

468

469

470

471

472

473

474

475

476

477

478

479

480

481

482

483

484

485

486

487

488

489

490

15. Sheahan TP, Sims AC, Graham RL, Menachery VD, Gralinski LE, Case JB, Leist SR, Pyrc K, Feng JY, Trantcheva I, Bannister R, Park Y, Babusis D, Clarke MO, Mackman RL, Spahn JE, Palmiotti CA, Siegel D, Ray AS, Cihlar T, Jordan R, Denison MR, Baric RS. 2017. Broad-spectrum antiviral GS-5734 inhibits both epidemic and zoonotic coronaviruses. Sci Transl Med 9.

16. Anthony SJ, Gilardi K, Menachery VD, Goldstein T, Ssebide B, Mbabazi R, Navarrete-Macias I, Liang E, Wells H, Hicks A, Petrosov A, Byarugaba DK, Debbink K, Dinnon KH, Scobey T, Randell SH, Yount BL, Cranfield M, Johnson CK, Baric RS, Lipkin WI, Mazet JA. 2017. Further Evidence for Bats as the Evolutionary Source of Middle East Respiratory Syndrome Coronavirus. MBio 8.

17. Scobey T, Yount BL, Sims AC, Donaldson EF, Agnihothram SS, Menachery VD, Graham RL, Swanstrom J, Bove PF, Kim JD, Grego S, Randell SH, Baric RS. 2013. Reverse genetics with a full-length infectious cDNA of the Middle East respiratory syndrome coronavirus. Proc Natl Acad Sci U S A 110:16157-16162.

18. Park JE, Li K, Barlan A, Fehr AR, Perlman S, McCray PB, Jr., Gallagher T. 2016. Proteolytic processing of Middle East respiratory syndrome coronavirus spikes expands virus tropism. Proc Natl Acad Sci U S A 113:12262-12267.

19. de Wilde AH, Raj VS, Oudshoorn D, Bestebroer TM, van Nieuwkoop S, Limpens RW, Posthuma CC, van der Meer Y, Barcena M, Haagmans BL, Snijder EJ, van den Hoogen BG. 2013. MERS-coronavirus replication induces severe in vitro cytopathology and is strongly inhibited by cyclosporin A or interferon-alpha treatment. J Gen Virol 94:1749-1760.

20. B SB, Orenstein JM, Fox LM, Randell SH, Rowley AH, Baker SC. 2009. Human airway epithelial cell culture to identify new respiratory viruses: coronavirus NL63 as a model. J Virol Methods 156:19-26.

21. Tekes G, Thiel HJ. 2016. Feline Coronaviruses: Pathogenesis of Feline Infectious Peritonitis. Adv Virus Res 96:193-218.

22. Song D, Park B. 2012. Porcine epidemic diarrhoea virus: a comprehensive review of molecular epidemiology, diagnosis, and vaccines. Virus Genes 44:167-175.

23. Corti D, Zhao J, Pedotti M, Simonelli L, Agnihothram S, Fett C, FernandezRodriguez B, Foglierini M, Agatic G, Vanzetta F, Gopal R, Langrish CJ, Barrett NA, Sallusto F, Baric RS, Varani L, Zambon M, Perlman S, Lanzavecchia A. 2015. Prophylactic and postexposure efficacy of a potent human monoclonal antibody against MERS coronavirus. Proc Natl Acad Sci U S A 112:10473-10478.

24. Pallesen J, Wang N, Corbett KS, Wrapp D, Kirchdoerfer RN, Turner HL, Cottrell CA, Becker MM, Wang L, Shi W, Kong WP, Andres EL, Kettenbach AN, Denison MR, Chappell JD, Graham BS, Ward AB, McLellan JS. 2017. Immunogenicity and structures of a rationally designed prefusion MERS-CoV spike antigen. Proc Natl Acad Sci U S A 114:E7348-E7357.

25. Zheng Y, Shang J, Yang Y, Liu C, Wan Y, Geng Q, Wang M, Baric R, Li F. 2018. Lysosomal Proteases Are a Determinant of Coronavirus Tropism. J Virol 92.

26. Yang Y, Du L, Liu C, Wang L, Ma C, Tang J, Baric RS, Jiang S, Li F. 2014. Receptor usage and cell entry of bat coronavirus HKU4 provide insight into bat-to-human transmission of MERS coronavirus. Proc Natl Acad Sci U S A 111:12516-12521.

27. Graham RL, Baric RS. 2010. Recombination, reservoirs, and the modular spike: mechanisms of coronavirus cross-species transmission. J Virol 84:3134-3146.

28. Ge XY, Li JL, Yang XL, Chmura AA, Zhu G, Epstein JH, Mazet JK, Hu B, Zhang W, Peng C, Zhang YJ, Luo CM, Tan B, Wang N, Zhu Y, Crameri G, Zhang SY, Wang LF, Daszak P, Shi ZL. 2013. Isolation and characterization of a bat SARS-like coronavirus that uses the ACE2 receptor. Nature 503:535-538. 
491

492

493

494

495

496

497

498

499

500

501

502

503

504

505

506

507

508

509

510

511

512

513

514

515

516

517

518

519

520

521

522

523

524

525

526

527

528

529

530

531

532

533

534

535

536

537

538

539

540
29. Luo CM, Wang N, Yang XL, Liu HZ, Zhang W, Li B, Hu B, Peng C, Geng QB, Zhu GJ, Li F, Shi ZL. 2018. Discovery of Novel Bat Coronaviruses in South China That Use the Same Receptor as Middle East Respiratory Syndrome Coronavirus. J Virol 92.

30. Klenk HD, Rott R, Orlich M, Blodorn J. 1975. Activation of influenza A viruses by trypsin treatment. Virology 68:426-439.

31. Luczo JM, Stambas J, Durr PA, Michalski WP, Bingham J. 2015. Molecular pathogenesis of $\mathrm{H} 5$ highly pathogenic avian influenza: the role of the haemagglutinin cleavage site motif. Rev Med Virol 25:406-430.

32. Clark SM, Roth JR, Clark ML, Barnett BB, Spendlove RS. 1981. Trypsin enhancement of rotavirus infectivity: mechanism of enhancement. J Virol 39:816-822.

33. Roivainen M, Hovi T. 1987. Intestinal trypsin can significantly modify antigenic properties of polioviruses: implications for the use of inactivated poliovirus vaccine. $\mathrm{J}$ Virol 61:3749-3753.

34. Hu H, Jung K, Vlasova AN, Chepngeno J, Lu Z, Wang Q, Saif LJ. 2015. Isolation and characterization of porcine deltacoronavirus from pigs with diarrhea in the United States. $\mathrm{J}$ Clin Microbiol 53:1537-1548.

35. Wicht O, Li W, Willems L, Meuleman TJ, Wubbolts RW, van Kuppeveld FJ, Rottier PJ, Bosch BJ. 2014. Proteolytic activation of the porcine epidemic diarrhea coronavirus spike fusion protein by trypsin in cell culture. J Virol 88:7952-7961.

36. Zhou P, Fan H, Lan T, Yang XL, Shi WF, Zhang W, Zhu Y, Zhang YW, Xie QM, Mani S, Zheng XS, Li B, Li JM, Guo H, Pei GQ, An XP, Chen JW, Zhou L, Mai KJ, Wu ZX, Li D, Anderson DE, Zhang LB, Li SY, Mi ZQ, He TT, Cong F, Guo PJ, Huang R, Luo Y, Liu XL, Chen J, Huang Y, Sun Q, Zhang XL, Wang YY, Xing SZ, Chen YS, Sun Y, Li J, Daszak P, Wang LF, Shi ZL, Tong YG, Ma JY. 2018. Fatal swine acute diarrhoea syndrome caused by an HKU2-related coronavirus of bat origin. Nature 556:255-258.

37. Li K, Wohlford-Lenane CL, Channappanavar R, Park JE, Earnest JT, Bair TB, Bates AM, Brogden KA, Flaherty HA, Gallagher T, Meyerholz DK, Perlman S, McCray PB, Jr. 2017. Mouse-adapted MERS coronavirus causes lethal lung disease in human DPP4 knockin mice. Proc Natl Acad Sci U S A 114:E3119-e3128.

38. Zeng LP, Gao YT, Ge XY, Zhang Q, Peng C, Yang XL, Tan B, Chen J, Chmura AA, Daszak P, Shi ZL. 2016. Bat Severe Acute Respiratory Syndrome-Like Coronavirus WIV1 Encodes an Extra Accessory Protein, ORFX, Involved in Modulation of the Host Immune Response. J Virol 90:6573-6582.

39. Zhou J, Li C, Zhao G, Chu H, Wang D, Yan HH, Poon VK, Wen L, Wong BH, Zhao X, Chiu MC, Yang D, Wang Y, Au-Yeung RKH, Chan IH, Sun S, Chan JF, To KK, Memish ZA, Corman VM, Drosten C, Hung IF, Zhou Y, Leung SY, Yuen KY. 2017. Human intestinal tract serves as an alternative infection route for Middle East respiratory syndrome coronavirus. Sci Adv 3:eaao4966.

40. Ding Y, He L, Zhang Q, Huang Z, Che X, Hou J, Wang H, Shen H, Qiu L, Li Z, Geng J, Cai J, Han H, Li X, Kang W, Weng D, Liang P, Jiang S. 2004. Organ distribution of severe acute respiratory syndrome (SARS) associated coronavirus (SARS-CoV) in SARS patients: implications for pathogenesis and virus transmission pathways. J Pathol 203:622-630.

41. Zhang X, Hasoksuz M, Spiro D, Halpin R, Wang S, Stollar S, Janies D, Hadya N, Tang Y, Ghedin E, Saif L. 2007. Complete genomic sequences, a key residue in the spike protein and deletions in nonstructural protein $3 \mathrm{~b}$ of US strains of the virulent and attenuated coronaviruses, transmissible gastroenteritis virus and porcine respiratory coronavirus. Virology 358:424-435.

42. Gallagher TM, Buchmeier MJ, Perlman S. 1992. Cell receptor-independent infection by a neurotropic murine coronavirus. Virology 191:517-522. 
43. Li W, Hulswit RJG, Widjaja I, Raj VS, McBride R, Peng W, Widagdo W, Tortorici MA, van Dieren B, Lang Y, van Lent JWM, Paulson JC, de Haan CAM, de Groot RJ, van Kuppeveld FJM, Haagmans BL, Bosch BJ. 2017. Identification of sialic acidbinding function for the Middle East respiratory syndrome coronavirus spike glycoprotein. Proc Natl Acad Sci U S A 114:E8508-E8517.

44. Anthony SJ, Gilardi K, Menachery VD, Goldstein T, Ssebide B, Mbabazi R, Navarrete-Macias I, Liang E, Wells H, Hicks A, Petrosov A, Byarugaba DK, Debbink K, Dinnon KH, Scobey T, Randell SH, Yount BL, Cranfield M, Johnson CK, Baric RS, Lipkin WI, Mazet JAK. 2017. Further Evidence for Bats as the Evolutionary Source of Middle East Respiratory Syndrome Coronavirus. Mbio 8.

45. Sims AC, Tilton SC, Menachery VD, Gralinski LE, Schafer A, Matzke MM, WebbRobertson BJ, Chang J, Luna ML, Long CE, Shukla AK, Bankhead AR, 3rd, Burkett SE, Zornetzer G, Tseng CT, Metz TO, Pickles R, McWeeney S, Smith RD, Katze MG, Waters KM, Baric RS. 2013. Release of severe acute respiratory syndrome coronavirus nuclear import block enhances host transcription in human lung cells. J Virol 87:38853902.

46. Sims AC, Burkett SE, Yount B, Pickles RJ. 2008. SARS-CoV replication and pathogenesis in an in vitro model of the human conducting airway epithelium. Virus Res 133:33-44.

47. Almazan F, DeDiego ML, Sola I, Zuniga S, Nieto-Torres JL, Marquez-Jurado S, Andres G, Enjuanes L. 2013. Engineering a replication-competent, propagationdefective Middle East respiratory syndrome coronavirus as a vaccine candidate. MBio 4:e00650-00613.

48. Agnihothram S, Menachery VD, Yount BL, Lindesmith LC, Scobey T, Whitmore A, Schafer A, Heise MT, Baric RS. 2018. Development of a Broadly Accessible Venezuelan Equine Encephalitis Virus Replicon Particle Vaccine Platform. Journal of Virology 92.

49. Bolles M, Deming D, Long K, Agnihothram S, Whitmore A, Ferris M, Funkhouser W, Gralinski L, Totura A, Heise M, Baric RS. 2011. A double-inactivated severe acute respiratory syndrome coronavirus vaccine provides incomplete protection in mice and induces increased eosinophilic proinflammatory pulmonary response upon challenge. $\mathrm{J}$ Virol 85:12201-12215.

50. Sheahan T, Whitemore A, Long K, Ferris M, Rockx B, Funkhoser W, Donaldson E, Gralinski L, Collier M, Heise M, Davis N, Johnston R, Baric RS. 2011. Successful vaccination strategies that protect aged mice from lethal challenge from influenza virus and heterologous severe acute respiratory syndrome coronavirus. J Virol 85:217-230.

51. Huynh J, Li S, Yount B, Smith A, Sturges L, Olsen JC, Nagel J, Johnson JB, Agnihothram S, Gates JE, Frieman MB, Baric RS, Donaldson EF. 2012. Evidence supporting a zoonotic origin of human coronavirus strain NL63. J Virol 86:12816-12825. 


\section{$582 \quad$ Figure Legends}

583 Figure 1. Exogenous trypsin rescues MERS-Uganda spike replication. A \& B) Structure of

584 the MERS-CoV spike trimer in complex with the receptor human DPP4 (red) from the A) side

585 and B) top. Consensus amino acids are outlined for the S1 (grey) and S2 (black) domains, with

586 PDF-2180 differences noted in magenta. C) Spike protein sequences of the indicated viruses

587 were aligned according to the bounds of total spike, S1, S2, and receptor-binding domain

588 (RBD). Sequence identities were extracted from the alignments, and a heatmap of sequence

589 identity was constructed using EvolView (www.evolgenius.info/evolview) with MERS-CoV as the

590 reference sequence. D) MERS-Uganda chimera stocks were grown in the presence or absence

591 of trypsin and were quantitated by plaque assay with a trypsin-containing overlay $(n=2)$. E)

592 Expression (qRT-PCR) of MERS-CoV (black) and MERS-Uganda (magenta) genomic RNA

593 following infection of Vero cells in the presence or absence of trypsin ( $n=3$ for each time point).

594 F) Protein expression of MERS-CoV nucleocapsid (N) and actin 18 hours post-infection of Vero

595 in the presence or absence of trypsin in the media. G) Phase-contrast and RFP expression

596 microscopy in Vero cells infected with MERS-CoV, MERS-Uganda spike chimera, or mock in

597 the presence or absence of trypsin.

598 Figure 2. MERS-Uganda spike chimera replicates in human cells. A \& B) Huh7 cells were

599 infected with MERS-CoV or MERS-Uganda chimeric viruses, showing A) microscopy images of

600 cell monolayer and RFP expression with and without trypsin treatment and B) $\mathrm{N}$ protein

601 expression following infection of Huh7 cells in the presence or absence of trypsin. C \& D)

602 Primary HAE cultures were infected with MERS-CoV or MERS-Uganda chimera, showing C)

603 RFP expression and D) genomic viral RNA following infection ( $n=3$ for 8, 24 HPI). E \& F) Caco-

6042 cells were infected with MERS-CoV or MERS-Uganda chimeric viruses expressing RFP,

605 showing E) microscopy images of cell monolayer and RFP expression with and without trypsin

606 treatment and F) N protein expression following infection of Caco-2 cells in the presence or 607 absence of trypsin. 
608 Figure 3. MERS-Uganda spike does not utilize DPP4 for infectfsion. A \& B) Vero cells were

609 infected with MERS-CoV or MERS-Uganda chimeric virus in the presence or absence of trypsin

610 and a blocking antibody against human DPP4. A) Fluorescent microscopy showing RFP

611 expression 24 hours post-infection for each treatment group. B) Western blot of $\mathrm{N}$ protein and

612 actin 24 hours post-infection.

613 Figure 4. Antibodies against MERS-CoV fail to neutralize MERS-Uganda chimera. A)

614 Structure of the MERS-CoV spike trimer with therapeutic antibody LCA60 bound adjacent to the

615 receptor-binding domain and the antibody G4 bound to the S2 portion. Consensus amino acids

616 are outlined for the S1 (grey) and S2 (black) domains, with PDF-2180 differences noted in

617 magenta. B \& C) Plaque neutralization curves for B) LCA60 and C) G4 with (solid) and without

618 (dotted) trypsin treatment for MERS-CoV (black) and MERS-Uganda chimera (magenta) ( $\mathrm{n}=3$

619 per concentration).

620 Figure 5. Exogenous trypsin rescues replication of HKU5-CoV. Vero cells were infected

621 with full-length HKU5-CoV in the presence or absence of trypsin. A) Expression (qRT-PCR) of

622 HKU5-CoV viral genome in the presence or absence of trypsin $(n=3)$. B) Immunoblotting of

623 HKU5 spike protein and cellular actin 24 and 48 hours post-infection with varying concentrations

624 of trypsin in the media. C) Immunoblotting for MERS $\mathrm{N}$ protein and cellular actin following

625 infection in the presence or absence of trypsin and human DPP4 antibody.

626 Figure 6. Barriers to zoonotic coronavirus emergence. Both receptor binding and protease

627 activitation are key correlates that govern zoonotic coronavirus emergence. A) A lack of

628 receptor binding with zoonotic CoVs precludes the infection of new host cells. B) Despite

629 receptor binding, the absence of compatible host proteases for spike cleavage restricts infection

630 in new hosts. C) The addition of exogenous protease overcomes the host protease barriers and

631 may or may not require receptor binding. 


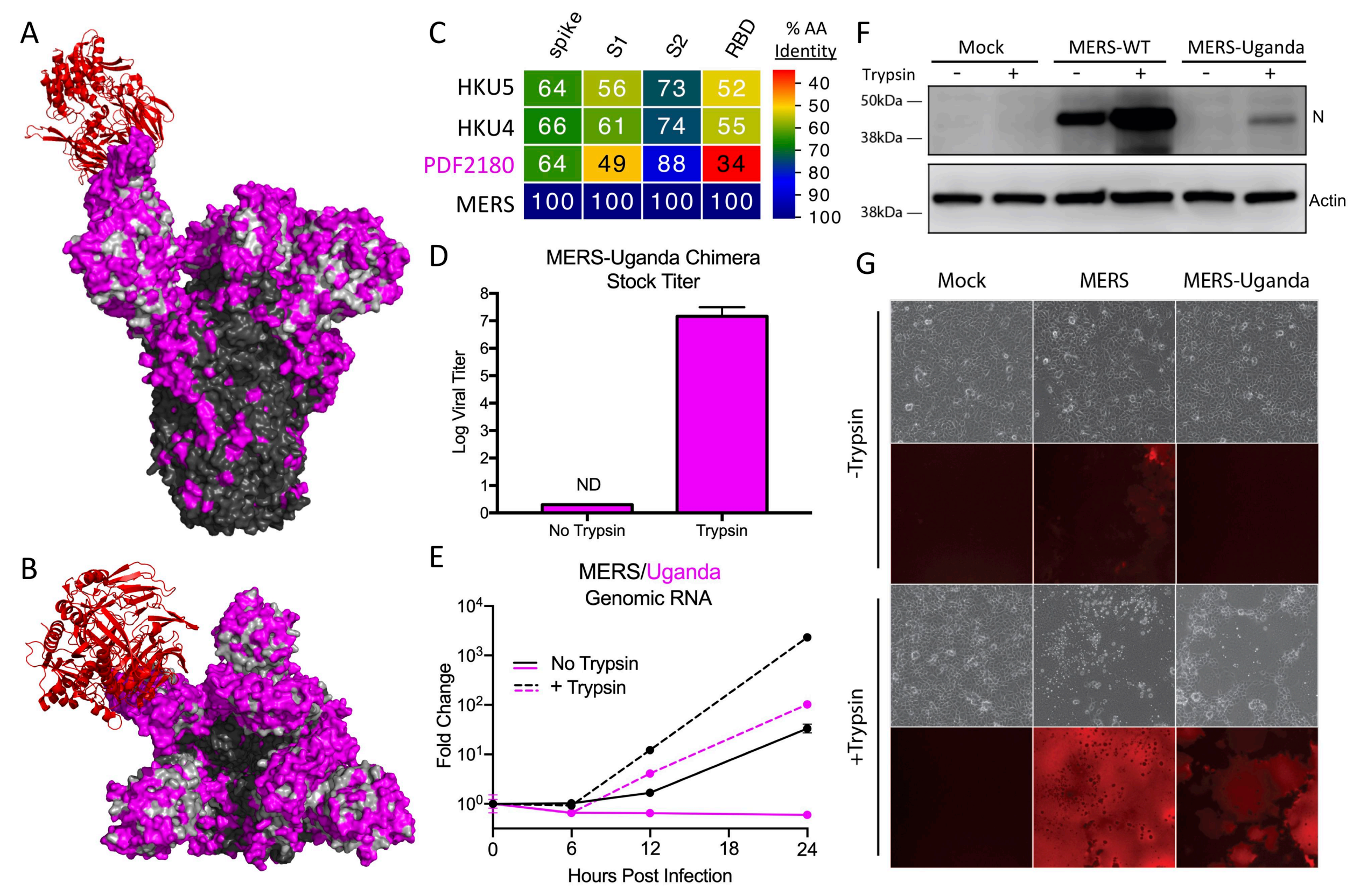




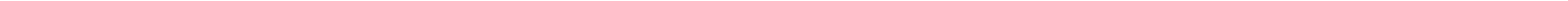


A

Mock
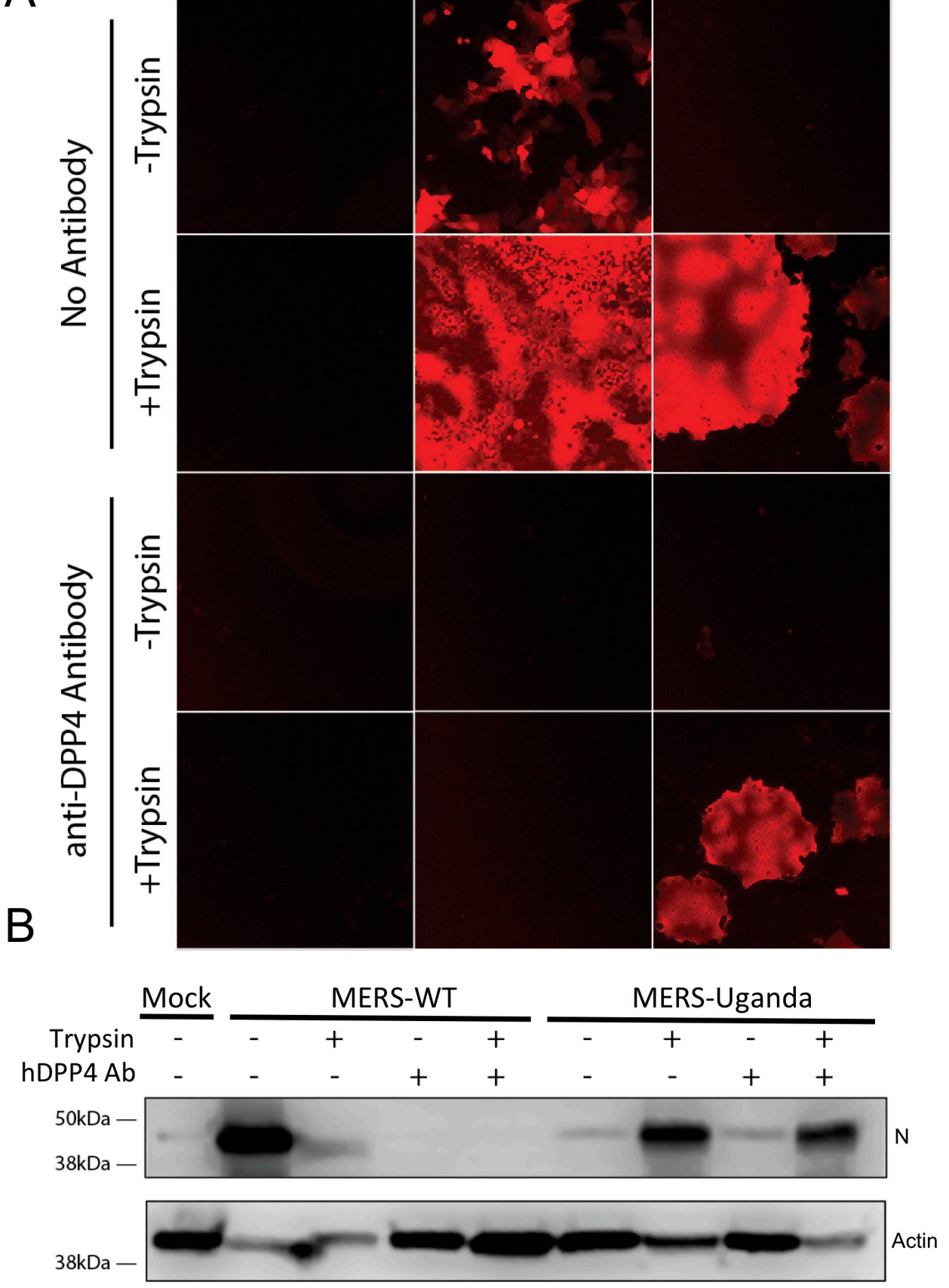


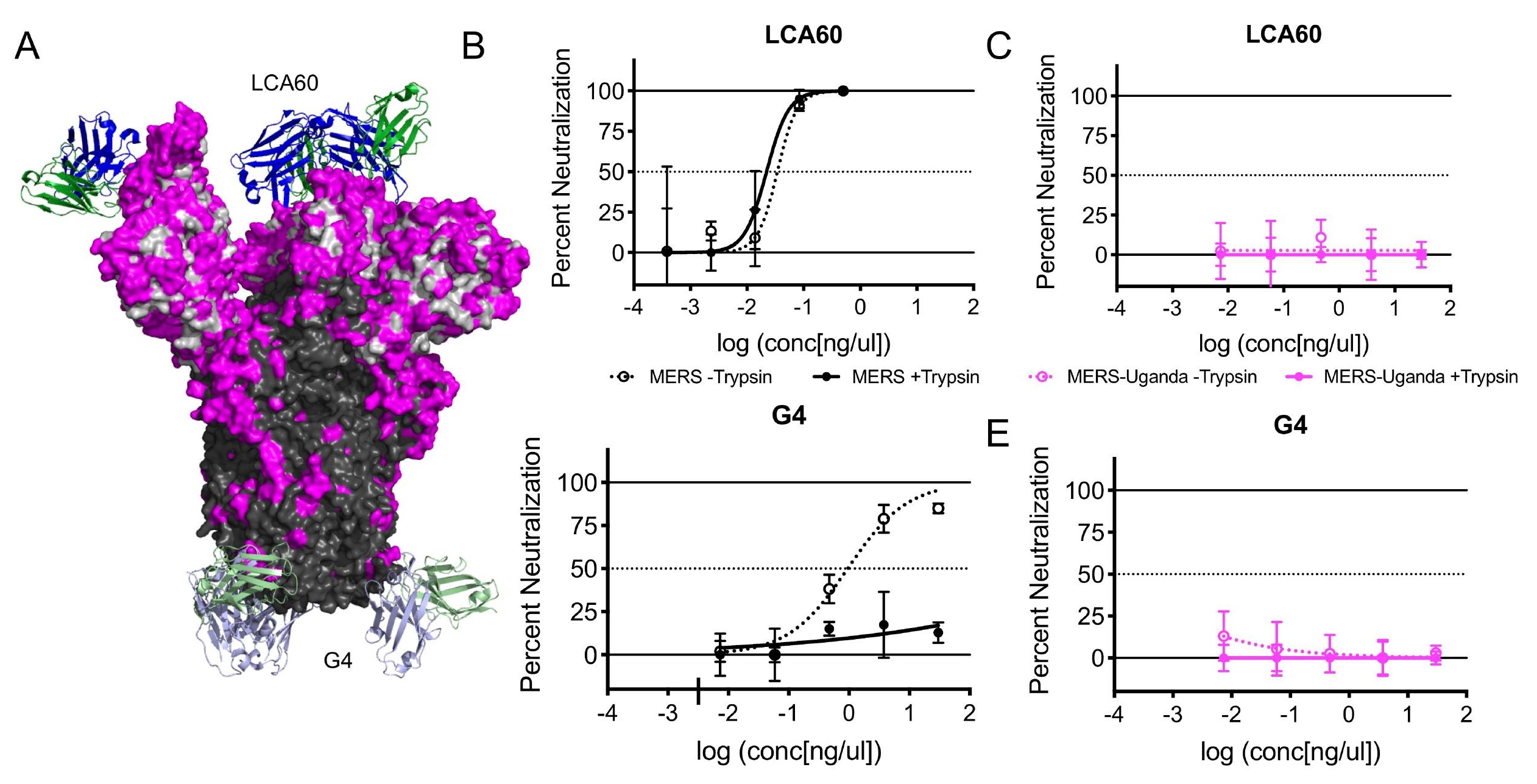



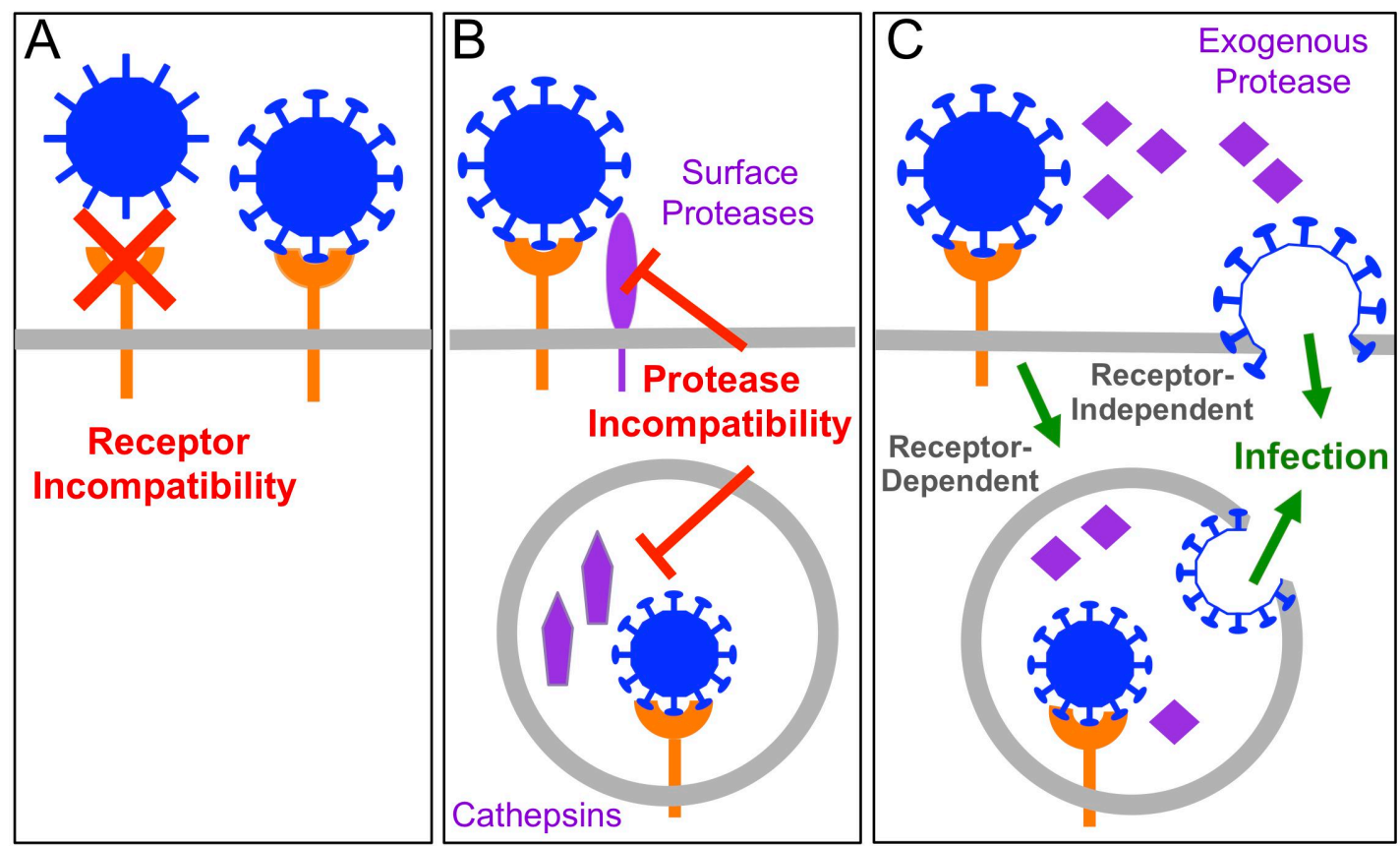